\title{
Bulked segregant analysis to identify SSR markers for loose smut resistance in bread wheat
}

\author{
Mohamed I. Hassan ${ }^{1 *}$, Amer F. Mahmoud ${ }^{2}$ and Karam A. Amein ${ }^{1}$ \\ ${ }^{1}$ Department of Genetics, Faculty of Agriculture, Assiut University, Assiut, Egypt. \\ ${ }^{2}$ Department of Plant Pathology, Faculty of Agriculture, Assiut University, Assiut, Egypt. \\ *Corresponding author: m_hassan79@aun.edu.eg
}

Received on: 8-2-2021

Accepted on: 5-3-2021

\begin{abstract}
The present study was conducted to evaluate $100 \mathrm{~F}_{8}$ recombinant inbred lines (RILs) derived from a cross between resistant and susceptible bread wheat landraces for loose smut caused by Ustilago tritici. Bulked segregant analysis (BSA) was also used to identify simple sequence repeats (SSR) markers associated with the resistance to loose smut. The artificial inoculation was repeated twice through two successive seasons (2017/2018 and 2018/2019) under greenhouse conditions, and responses of tested genotypes against loose smut were evaluated in 2018/2019 and 2019/2020 seasons. Highly significant differences $(P<0.01)$ were observed for loose smut incidence among the tested RILs, indicating a considerable genetic variation. On average, loose smut incidence (LSI \%) of the tested RILs ranged from 0\% in RIL-64 to $97.5 \%$ in RIL-74 and RIL-93, with an average of 47.5\%. Out of 100 RILs, the RIL-64 was considered as an immune genotype (no symptoms were observed on any plant), RIL-13, RIL-16, RIL-27 and RIL-37 were highly resistant (LSI= 5.0, 5.0, 2.5, 2.5\%, respectively), and RIL-2, RIL-50 and RIL-96 were resistant to loose smut (LSI $=7.5,7.5$ and $10.0 \%$, respectively), suggesting the usefulness of these genotypes for developing wheat varieties resistant to loose smut. BSA with forty two SSRs markers identified five positive alleles generated by Xgwm18-1B, Xgwm95-2A, Xgwm294-2A, Xgwm186-5A and Xgwm293-5A markers that were associated with loose smut resistance in the tested population, suggesting that several loci could be contributed to loose smut resistance in wheat. However further studies are still required to confirm usefulness of these markers in breeding programs.
\end{abstract}

KEYWORDS: Bread wheat, Loose smut, Ustilago tritici, Disease resistance, Bulked Segregant Analysis, SSRs.

\section{INTRODUCTION}

Loose smut of wheat is a seed borne disease caused by the fungus Ustilago tritici (Kumar et al., 2018; Chakraborty et al., 2021). It is considered as a common disease in different wheat-growing regions worldwide, causing significant reductions of wheat productivity (Thambugala et al., 2020). In Egypt, loose smut is ranked as the second serious disease infecting wheat following rusts, and it is also considered as a disease of economic important due to its negative effects on grain yield and quality of wheat (Gad et al., 2019). The pathogen remains as a dormant mycelium within the mature seed and germinates with germinating seeds. After seed germination, the mycelium grows in the crown node and later invades inflorescence tissues (Yadav et al., 2020). The pathogens develop systemically in the host plant during growth of the plant, and finally the spike floral tissues of the infected plants are replaced with black masses of teliospores, causing a significant yield reduction (Kumar et al., 2018).

Since loose smut pathogen remains dormant in the mature seed (Yadav et al., 2020), the smut fungi have been difficult to control with surface fungicide treatments. Therefore, resistant wheat genotypes have been long used as an effective method for loose smut management in wheat (Nielsen, 1983). Furthermore, the development of resistant cultivars is most desirable as an environment-friendly strategy for management of the disease (Menzies, 2008). The infected seed as well as the infected plant cannot be distinguished from a healthy one until the head (spike) starts to emerge. Unlike, loose smut can be easily recognized at the stage of spike emergence as individual grains are completely replaced with masses of black fungal spores (Kumar et al., 2018).

Interestingly, it has been reported that the loose smut resistance in wheat might be inherited as a qualitative or a quantitative trait (Knox et al., 2014). However, different gene actions were reported in wheat, which were depending on the studied varieties and the pathogens (Nielsen and Thomas, 1996; Knox and Menzies, 2012). The additive gene actions were revealed in most cases, and the duplicate complementary action of different 


\section{Scientific Journal of Agricultural Sciences 3 (1): 119-130, 2021}

genes was also detected (Syukov and Porotkin, 2015). Multiple genes for loose smut resistance have been previously identified on different wheat chromosomes (Knox et al., 2002; McIntosh et al., 2013; Kassa et al., 2014; Syukov et al., 2015). Different major genes were also found to be located on different wheat chromosomes (Knox and Menzies, 2012). In addition, several quantitative trait loci (QTLs) governing loose smut resistance were previously mapped on different wheat chromosomes by using molecular markers (Toor et al., 2013; Knox et al., 2014; Kumar et al., 2018; Thambugala et al., 2020).

The association between SSR markers and genes controlling loose smut resistance has been reported in wheat (Randhawa et al., 2009; Knox et al., 2014; Kumar et al., 2018; Kumar et al., 2021). Bulked segregant analysis (BSA) developed by Michelmore et al. (1991) has been proven as a rapid and efficient method to identify molecular markers for important traits (Torres et al., 2010; Barakat et al., 2011; Hassan et al., 2016). In addition, BSA has been used to identify molecular markers associated with loose smut resistance in wheat (Kassa et al., 2014; Kassa et al., 2015). Since chromosomal locations of numerous SSR markers have been reported in different species, the map location of closely linked QTLs can be determined using BSA without the need for genotyping every individual in the population (Quarrie et al., 1999).

Therefore, in the present study, a population of $100 \mathrm{~F}_{8}$ recombinant inbred lines (RILs) derived from a cross between two Egyptian bread wheat landraces were evaluated for the resistance to loose smut under greenhouse conditions. The objectives were (1) to assess the responses of tested RILs against loose smut caused by Ustilago tritici; (2) to identify resistant bread wheat genotypes to be used in breeding programs; and (3) to identify SSR markers associated with loose smut resistance in the RIL population using BSA.

\section{MATERIALS AND METHODS}

\subsection{Plant material and greenhouse experiments:}

The plant material used in this study consisted of $100 \mathrm{~F}_{8}$ recombinant inbred lines (RILs) of bread wheat (Triticum aestivum L.) which derived from a cross between two Egyptian landraces, quite variable in their resistance against loose smut. The artificial infection and evaluation of tested RILs against loose smut were carried out at the greenhouse of Department of Plant Pathology, Faculty of Agriculture, Assiut University, Egypt during three wheat growing seasons. The artificial inoculation of the tested RILs with $U$. tritici was repeated twice through 2017/2018 and 2018/2019 seasons, and evaluating responses of inoculated wheat genotypes against loose smut was carried out during 2018/2019 and 2019/2020 seasons.

\subsection{Artificial infection and disease assessment:}

The artificial inoculation of tested RILs with $U$. tritici was carried out in the greenhouse following Kumar et al. (2018). In brief, twenty seeds of each RIL were sown on a normal sowing date in sterilized pots $(25 \mathrm{~cm}$ in diameter) containing a peat/sand mixture, following a randomized complete blocks design (RCBD) with four replicates (pots) for each RIL. Syringe technique of spore inoculation was used at the mid-anthesis of wheat plants. A teliospore suspension of $U$. tritici was prepared (1g of teliospores/1L of distilled water). On the morning, all florets on each spike of grown plants were inoculated with the teliospore suspension using a hypodermic needle. The inoculated plants were labeled, and the spikes were harvested at the maturity and the grains were stored for disease assessment in the next season. For disease assessment (next season), twenty seeds of each RIL collected from the previous season were sown on a normal sowing date in sterilized pots following a RCBD with four replicates for each RIL. At the maturity, loose smut incidence (LSI \%) of each RIL was determined following Kumar et al. (2018) and Thambugala et al. (2020) as follows:

$$
\text { LSI }(\%)=\frac{\text { Number of smutted plants }}{\text { Total number of plants }} \times 100
$$

The reactions of tested RILs against loose smut were assessed based on the disease incidence (Mean LSI, averaged two years) using the rating scale adopted from llyas et al. (1990) as follows:

- $\mathrm{LSI}=0 \%$ : Immune (I);

- $\mathrm{LSI}=0.1$ to $<6 \%$ : Highly resistant (HR);

- $\mathrm{LSI}=6$ to $<11 \%$ : Resistant (R);

- $\mathrm{LSI}=11$ to $<21 \%$ : Moderately resistant (MR);

- $\mathrm{LSI}=21$ to $<31 \%$ : Moderately susceptible (MS);

- $\mathrm{LSI}=31$ to $<51 \%$ : Susceptible (S);

- $\mathrm{LSI}=51$ to $100 \%$ : Highly Susceptible (HS);

\subsection{Statistical analysis}

The data of LSI (\%) of the tested RILs in 2018/19 and 2019/20 seasons were subjected to a combined analysis of variance (ANOVA) across the two environments (seasons) to test the significance of differences among genotypes $(G)$ and environments (E) and the significance of $G \times E$ interaction. The significance of differences for LSI $\%$ was tested using Least Significant Difference (LSD) at 5\% probability. The coefficient of variation (\%) was calculated. Pearson's correlation coefficient 
between LSI of the two years was also estimated.

\subsection{Bulked segregant analysis (BSA)}

To identify SSR markers associated with loose smut resistance in specific genomic regions, the $\mathrm{F}_{8}$ RILs population was subjected to BSA (Quarrie et al., 1999) with a total of forty two wheat microsatellites or SSR primer pairs representing all wheat chromosomes of $\mathrm{A}, \mathrm{B}$ and $\mathrm{D}$ genomes of wheat (Table 1). The highly resistant seven RILs as well as the highly susceptible seven RILs were selected from the $\mathrm{F}_{8}$ RILs population based on mean LSI (averaged two years) and used to construct two DNA bulks for BSA. Genomic DNA extraction was performed using Murray and Thompson (1980) method. Aliquots of DNA from each RIL in each group were mixed to produce resistant and susceptible DNA bulks. Sequences of SSR primers, chromosomal locations and PCR conditions were obtained by the GrainGenes Database (http://wheat.pw.usda.gov). PCR amplifications were performed in a SensoQuest LabCycler with OnePCR master mix (GeneDireX, Inc.). PCR products were separated on $2.5 \%$ agarose gels in TBE buffer (0.5 X). A 100bp DNA Ladder was used to estimate the size of amplified DNA fragments (bands). Putative polymorphisms between resistant and susceptible bulks were detected for each marker.

\section{RESULTS AND DISCUSSION}

A total of $100 \mathrm{~F}_{8}$ RILs of bread wheat were evaluated for their responses against loose smut caused by Ustilago tritici under greenhouse conditions. Phenotypic evaluation of loose smut requires two successive seasons; the first season to inoculate tested wheat genotypes with $U$. tritici, and the second to evaluate response of the inoculated plants to the infection (Kumar et al., 2018). In the present study, the artificial inoculation was repeated twice during 2017/2018 and 2018/2019 seasons, and the response of tested RILs were evaluated for two years after each inoculation. Disease symptoms were easily detected at the spike emergence stage as the floral tissues of the infected spike (head) were completely replaced with masses of black spores, as shown in Fig.1. Consequently, the infected plant produces smutted heads instead of grains, and thereby loose smut can cause significant reductions of wheat grain yield (Thambugala et al., 2020). It has been reported that the reduction in grain yield is approximately equal to the percentage of smutted heads on the plant (Gad et al., 2019).

The combined ANOVA across the two environments (seasons) reveled highly significant differences $(P<0.01)$ for loose smut incidence (LSI $\%)$ among the tested RILs, indicating the presence of a considerable genetic variation. A significant difference $(P<0.05)$ was also observed between the two environments. However, the genotypes-byenvironment interaction was non-significant (Table 2). The frequency distribution of LSI (\%) in the $10 \mathrm{~F}_{8}$ RILs population in 2018/2019 and 2019/20220 seasons (Fig.2) indicated transgressive segregation of different genes controlling loose smut, as previously reported in wheat (Knox et al., 1999; Kumar et al., 2018).

A highly significant and positive correlation was observed between LSI (\%) of the two growing seasons $(\mathrm{r}=0.86 ; P<0.01)$. On average, the LSI of the RILs population ranged from $0 \%$ in RIL-64 to 97.5\% in RIL-74 and RIL-93, with an average of $47.5 \%$. Based on the rating scale described by llyas et al. (1990), out of 100 RILs evaluated, the RIL-64 was considered as an immune genotype (no symptoms were observed on any plant). In addition, 4 RILs were highly resistant (RIL-13, RIL-16, RIL27 and RIL-37) and 3 RILs were resistant to loose smut (RIL-2, RIL-50 and RIL-96). In addition, 9 RILs were moderately resistant, 13 RILs were moderately susceptible, 33 RILs were susceptible and 37 RILs were highly susceptible to loose smut (Table 3).

In Egypt, a large number of wheat landraces possess considerable genetic diversity including resistance genes against different plant pathogens. The RILs population evaluated in the present study was derived from a cross between two Egyptian landraces, quit variable in their resistance to loose smut. In this regard, it has been reported that old varieties and local populations or landraces are valuable genetic resources for plant breeders due to their adaptability to marginal environments and higher resistance to pathogens (Pietrusińska et al., 2018). Unlike, the pure genotypes may lack the wide adaptation and the diverse genetic background already present in landraces (Jaradat, 2013). Thus, it is of great importance to identify resistant genetic resources from landraces to be used in wheat breeding programs (Mahmoud et al., 2015). Furthermore, wheat landraces is a potential source of novel resistance genes (Sthapit et al., 2014). Developing resistant wheat cultivars is also considered as the most desirable and environmentfriendly strategy for the disease management (Menzies, 2008). Therefore, RILs identified in the present study as immune, highly resistant as well as resistant to loose smut may possess diverse resistance genes, and thereby can be considered as valuable genetic resources for developing diseaseresistant bread wheat varieties through breeding programs.

In the present study, the RILs population was subjected to bulked segregant analysis (BSA) to identify SSR markers for loose smut resistance. 
Scientific Journal of Agricultural Sciences 3 (1): 119-130, 2021

Table 1. Names, chromosomal locations, sequences of forward and reverse primers and annealing temperature ${ }^{\circ} \mathrm{C}(\mathrm{Tm})$ of 42 SSR markers used for BSA.

\begin{tabular}{|c|c|c|c|}
\hline Name & Forward primer (5' - 3') & Reverse primer (5' - 3') & $\begin{array}{l}\text { Tm } \\
\left({ }^{\circ} \mathrm{C}\right)\end{array}$ \\
\hline Xgwm33-1A & GGAGTCACACTTGTTTGTGCA & CACTGCACACCTAACTACCTGC & 60 \\
\hline Xgwm497-1A & GTAGTGAAGACAAGGGCATT & CCGAAAGTTGGGTGATATAC & 55 \\
\hline Xgwm95-2A & GATCAAACACACACСССТCC & AATGCAAAGTGAAAAACCCG & 60 \\
\hline Xgwm294-2A & GGATTGGAGTTAAGAGAGAACCG & GCAGAGTGATCAATGCCAGA & 55 \\
\hline Xgwm339-2A & ААТTTTСТTССТСАСТТАТТ & AAACGAACAACCACTCAATC & 50 \\
\hline Xgwm356-2A & AGCGTTCTTGGGAATTAGAGA & CCAATCAGCCTGCAACAAC & 55 \\
\hline Xgwm155-3A & СААТСАТTТСССССТСC & AATCATTGGAAATCCATATGCC & 60 \\
\hline Xgwm160-4A & TTCAATTCAGTCTTGGCTTGG & CTGCAGGAAAAAAAGTACACCC & 55 \\
\hline Xgwm165-4A & TGCAGTGGTCAGATGTTTCC & СTTTTCTTTCAGATTGCGCC & 60 \\
\hline Xgwm186-5A & GCAGAGCCTGGTTCAAAAAG & CGCCTCTAGCGAGAGCTATG & 60 \\
\hline Xgwm291-5A & CATCCCTACGCCACTCTGC & AATGGTATCTATTCCGACCCG & 60 \\
\hline Xgwm292-5A & TCACCGTGGTCACCGAC & CCACCGAGCCGATAATGTAC & 60 \\
\hline Xgwm293-5A & TACTGGTTCACATTGGTGCG & TCGCCATCACTCGTTCAAG & 55 \\
\hline Xbarc186-5A & GGAGTGTCGAGATGATGTGGAAAC & CGCAGACGTCAGCAGCTCGAGAGG & 60 \\
\hline Xgwm459-6A & ATGGAGTGGTCACACTTTGAA & AGCTTCTCTGACCAACTTCTCG & 55 \\
\hline Xbarc113-6A & GCGCACAACAACGGACACTTAACAAT & GGGACTCATTTAGCTTCTACTCGCCATTA & 50 \\
\hline Xgwm63-7A & TCGACCTGATCGCCCCTA & CGCCCTGGGTGATGAATAGT & 60 \\
\hline Xwmc273-7A & AGTTATGTATTCTCTCGAGCCTG & GGTAACCACTAGAGTATGTCCTT & 50 \\
\hline Xwmc596-7A & TCAGCAACAAACATGCTCGG & CCCGTGTAGGCGGTAGCTCTT & 60 \\
\hline Xwmc603-7A & ACAAACGGTGACAATGCAAGGA & CGCCTCTCTCGTAAGCCTCAAC & 60 \\
\hline Xbarc121-7A & ACTGATCAGCAATGTCAACTGAA & CCGGTGTCTTTCCTAACGCTATG & 50 \\
\hline Xgwm18-1B & GGTTGCTGAAGAACCTTATTTAGG & TGGCGCCATGATTGCATTATCTTC & 50 \\
\hline Xgwm111-2B & GTTGCACGACCTACAAAGCA & ATCGCTCACTCACTATCGGG & 55 \\
\hline Xgwm389-3B & ATCATGTCGATCTCCTTGACG & TGCCATGCACATTAGCAGAT & 60 \\
\hline Xgwm493-3B & TTCCCATAACTAAAACCGCG & GGAACATCATTTCTGGACTTTG & 60 \\
\hline Xgwm533-3B & AAGGCGAATCAAACGGAATA & GTTGCTTTAGGGGAAAAGCC & 60 \\
\hline Xgwm566-3B & TCTGTCTACCCATGGGATTTG & CTGGCTTCGAGGTAAGCAAC & 60 \\
\hline Xgwm113-4B & ATTCGAGGTTAGGAGGAAGAGG & GAGGGTCGGCCTATAAGACC & 55 \\
\hline Xgwm513-4B & ATCCGTAGCACCTACTGGTCA & GGTCTGTTCATGCCACATTG & 60 \\
\hline Xgwm408-5B & TCGATTTATTTGGGCCACTG & GTATAATTCGTTCACAGCACGC & 55 \\
\hline Xgwm626-6B & GATCTAAAATGTTATTTTCTCTC & TGACTATCAGCTAAACGTGT & 50 \\
\hline Xwmc398-6B & GGAGATTGACCGAGTGGAT & CGTGAGAGCGGTTCTTTG & 60 \\
\hline Xgwm577-7B & ATGGCATAATTTGGTGAAATTG & TGTTTCAAGCCCAACTTCTATT & 55 \\
\hline Xgwm458-1D & TTCGCAATGTTGATTTGGC & TTCGCAATGTTGATTTGGC & 60 \\
\hline Xbarc229-1D & GGCCGCTGGGGATTGCTATGAT & TCGGGATAAGGCAGACCACAT & 55 \\
\hline Xgwm261-2D & CTCCCTGTACGCCTAAGGC & CTCGCGCTACTAGCCATTG & 55 \\
\hline Xgwm484-2D & ACATCGCTCTTCACAAACCC & AGTTCCGGTCATGGCTAGG & 55 \\
\hline Xwmc601-2D & ACAGAGGCATATGCAAAGGAGG & СтTGTCTCTTTATCGAGGGTGG & 60 \\
\hline Xgwm3-3D & AATATCGCATCACTATCCCA & AATATCGCATCACTATCCCA & 55 \\
\hline Xgwm190-5D & GTGCTTGCTGAGCTATGAGTC & GTGCCACGTGGTACCTTTG & 60 \\
\hline Xgwm325-6D & тTTCTTCTGTCGTTCTCTTCCC & TTTTTACGCGTCAACGACG & 60 \\
\hline Xgwm437-7D & GATCAAGACTTTTGTATCTCTC & GATGTCCAACAGTTAGCTTA & 50 \\
\hline
\end{tabular}



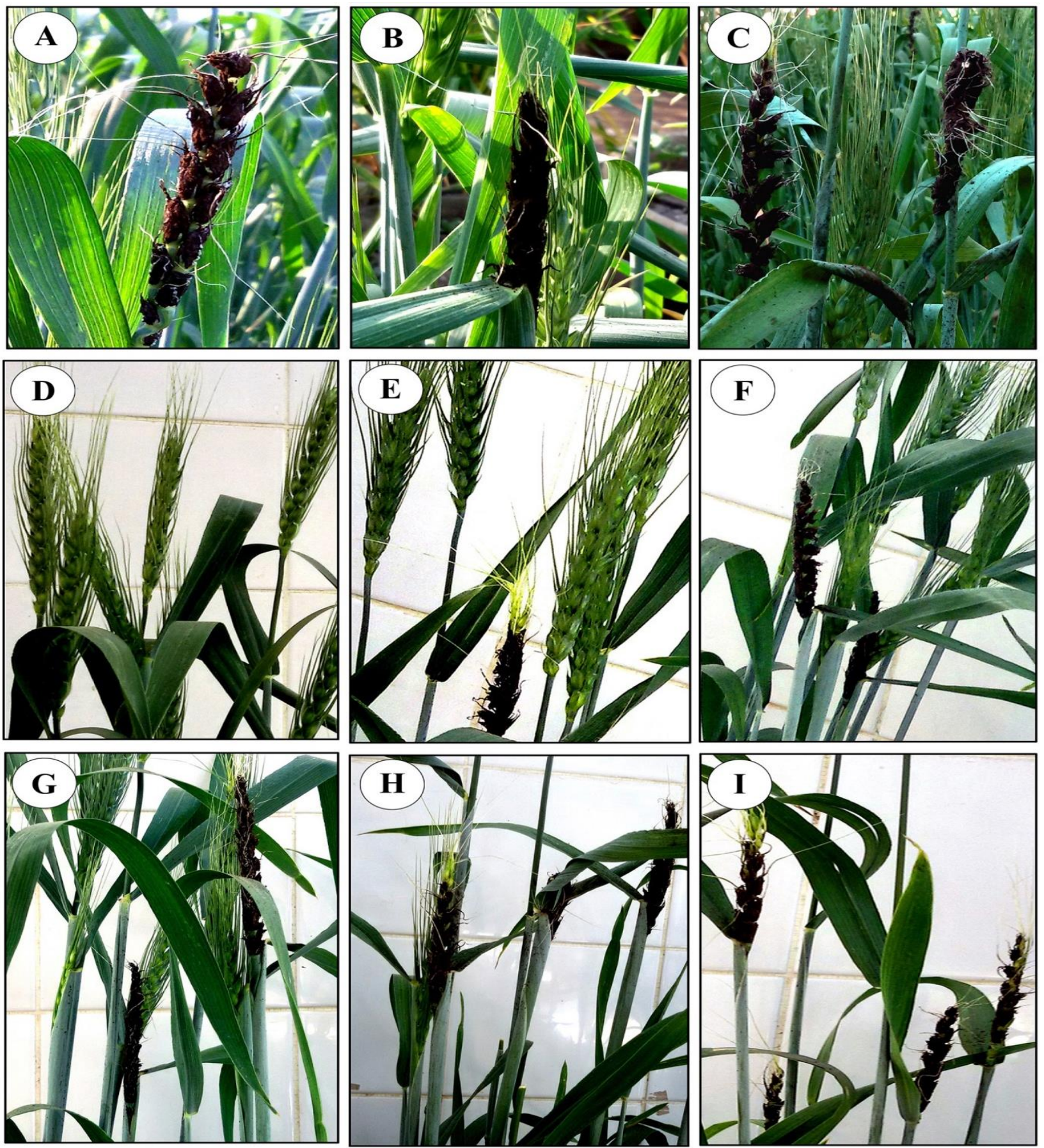

Fig.1. Loose smut symptoms caused by Ustilago tritici on different RILs of bread wheat: (A, B and C) show floral parts of different wheat spikes that were completely replaced by masses of black teliospores, (D) shows a RIL with no symptoms on any plant (immune), and (E to I) show RILs with difference loose smut incidence.

Table 2. The combined ANOVA of loose smut incidence across two environments (2018/2019 and 2019/2020 seasons) in 100 RILs population of bread wheat.

\begin{tabular}{llll}
\hline Source of variance & d.f & Sum of squares & Mean square \\
\hline Environments (E) & 1 & 1922.0 & $1922.0^{*}$ \\
Replicates within E & 6 & 1268.0 & 211.3 \\
Genotypes (G) & 99 & 631422.0 & $6378.0^{* *}$ \\
G×E interaction & 99 & 43478.0 & 439.2 \\
\hline Pooled error & 594 & 278932.0 & 469.6 \\
\hline
\end{tabular}

$*$ and $* *$ indicate significant differences at 0.05 and 0.01 probability. 

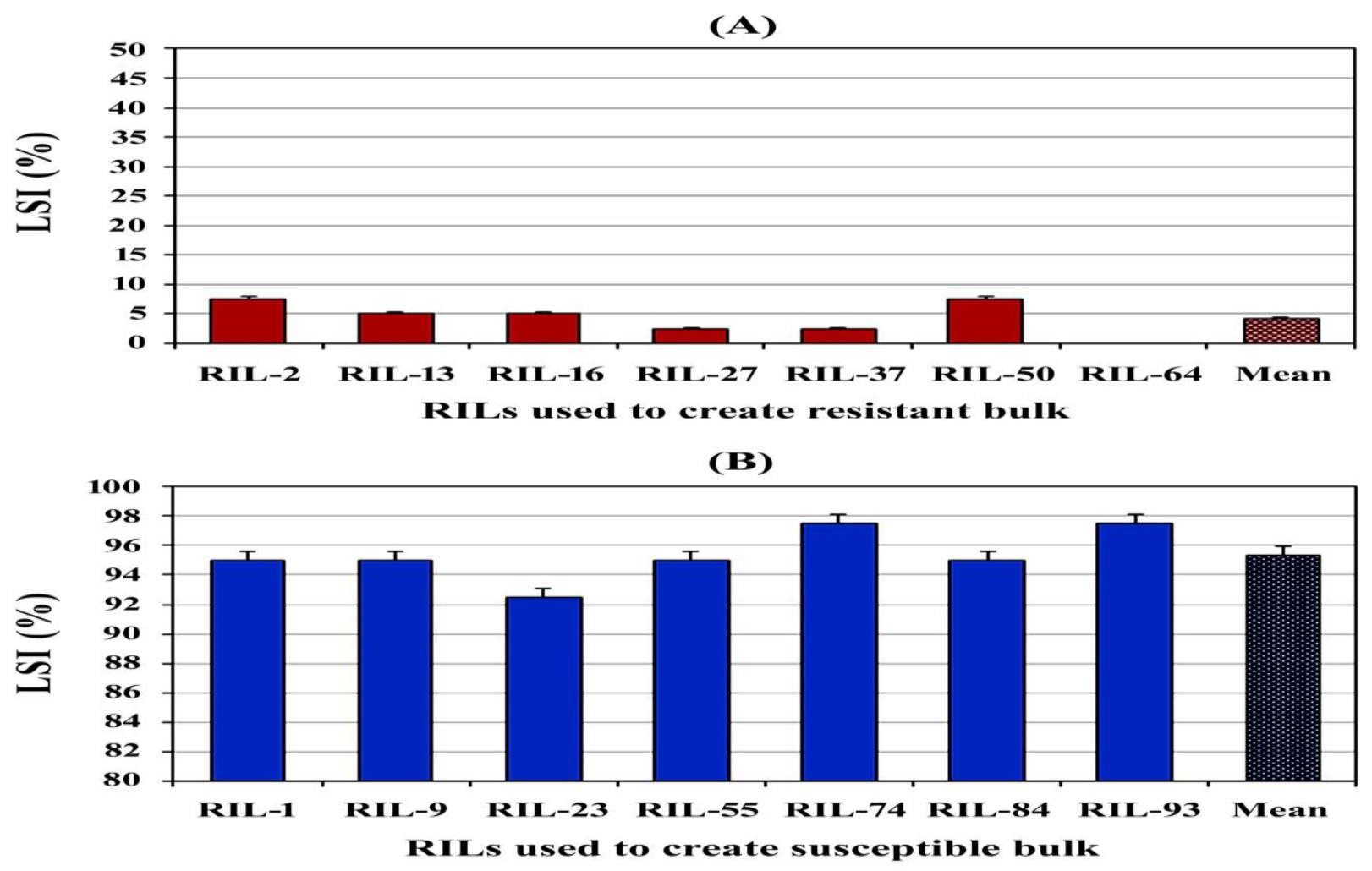

Fig.2. Loose smut incidence (LSI \%) of RILs used to create resistant (A) and susceptible (B) bulks for BSA.

The immune and highly resistant seven RILs showing the lowest LSI (\%) as well as the highly susceptible seven RILs showing the highest LSI (\%) averaging two years were used to construct two DNA bulks for BSA. Mean LSI of the RILs used to construct the resistant bulk; namely RIL-2, RIL-13, RIL-16, RIL-27, RIL-37, RIL-50 and RIL-64 were 7.5, 5.0, 5.0, 2.5, 2.5, 7.5 and 0\%, respectively, with an average of $4.3 \%$. Meanwhile, mean LSI of the RILs used to construct the susceptible bulk; namely RIL-1, RIL-9, RIL-23, RIL-55, RIL-74, RIL-84 and RIL-93 were 95.0, 95.0, 92.5, 95.0, 97.5, 95.0 and $97.5 \%$, respectively, with an average of $95.4 \%$ (Table 3; Fig. 3).

The PCR assays with SSR markers generated different number of bands (alleles) which were depending on the primers used, indicating the presence of allelic diversity among SSRs (Ravi et al., 2003; Ram et al., 2007). It has been reported that such variation in the allelic diversity is due to several factors including the structure of primers used and number of annealing sites in the genome (Muralidharan and Wakeland, 1993).

Out of forty two SSRs markers used with BSA, five SSRs generated nine polymorphic bands, which were able to distinguish the resistant from susceptible bulk (Fig.4 to Fig.6). Of which, five positive bands (alleles) generated by the markers Xgwm18-1B (192 bp), Xgwm95-2A (160 bp), Xgwm294-2A (350 bp), Xgwm186-5A (188 bp) and Xgwm293-5A (94 bp) were associated with the resistance RILs, while four alleles generated by the markers Xgwm95-2A (146 bp), Xgwm294-2A (310 bp), Xgwm186-5A (200 bp) and Xgwm293-5A (118 bp) were associated with susceptible RILs (Table 4). In accordance, BSA has been used by Kassa et al. (2014) and Kassa et al. (2015) to identify molecular markers for loose smut resistance in wheat. Furthermore, BSA has been widely used to identify SSR markers associated with important traits (Torres et al., 2010; Barakat et al., 2011; Hassan et al., 2016; Mahmoud and Hassan, 2020). The association between SSR markers and genes or QTLs controlling loose smut resistance has been also reported in wheat (Randhawa et al., 2009; Knox et al., 2014; Kumar et al., 2018). Multiple genes controlling loose smut resistance have been previously identified in wheat on different wheat chromosomes (Knox et al., 2002; McIntosh et al., 2013; Kassa et al., 2014; Syukov et al., 2015). Of which, Ut1 and Ut2 were found to be located on chromosome $6 \mathrm{~A}, \mathrm{Ut} 3$ and Ut4 on $7 \mathrm{~B}, \mathrm{Ut} 5$ on $2 \mathrm{~B}$, Ut6 on $5 B$, Ut7 on $7 A$, Ut8 on $3 A$, Ut9 on $6 B$ and Ut10 on 6D (Knox and Menzies, 2012; McIntosh et al., 2013; Kassa et al., 2014; Kassa et al., 2015; Knox et al., 2014; Syukov et al., 2015; Serfling et al., 2017). In addition, different QTLs governing loose smut resistance were previously mapped by using molecular markers on chromosomes 1B, 3A, $3 \mathrm{~B}, 4 \mathrm{~B}, 5 \mathrm{~B}, 6 \mathrm{~A}, 6 \mathrm{~B}, 6 \mathrm{D}, 7 \mathrm{~A}$ and $7 \mathrm{~B}$ of wheat (Toor et al., 2013; Knox et al., 2014; Kumar et al., 2018; Thambugala et al., 2020). 
Mohamed I. Hassan et al., 2021

Table 3. Response of $100 \mathrm{~F}_{8}$ RILs against loose smut (averaged 2018/2019 and 2019/2020 seasons).

\begin{tabular}{|c|c|c|c|c|c|c|c|c|}
\hline No. & LSI (\%) & Reaction & No. & LSI (\%) & Reaction & No. & LSI (\%) & Reaction \\
\hline 1 & 95.0 & HS & 35 & 35.0 & $\mathbf{S}$ & 69 & 35.0 & $\mathbf{S}$ \\
\hline 2 & 7.5 & $\mathbf{R}$ & 36 & 75.0 & HS & 70 & 32.5 & $\mathbf{S}$ \\
\hline 3 & 27.5 & MS & 37 & 2.5 & HR & 71 & 82.5 & HS \\
\hline 4 & 40.0 & $\mathbf{S}$ & 38 & 77.5 & HS & 72 & 25.0 & MS \\
\hline 5 & 80.0 & HS & 39 & 20.0 & MR & 73 & 65.0 & HS \\
\hline 6 & 35.0 & $\mathbf{S}$ & 40 & 12.5 & MR & 74 & 97.5 & HS \\
\hline 7 & 80.0 & HS & 41 & 80.0 & HS & 75 & 92.5 & HS \\
\hline 8 & 80.0 & HS & 42 & 60.0 & HS & 76 & 45.0 & $\mathbf{S}$ \\
\hline 9 & 95.0 & HS & 43 & 45.0 & $\mathbf{S}$ & 77 & 40.0 & $\mathbf{S}$ \\
\hline 10 & 90.0 & HS & 44 & 32.5 & $\mathbf{S}$ & 78 & 80.0 & HS \\
\hline 11 & 77.5 & HS & 45 & 32.5 & $\mathbf{S}$ & 79 & 22.5 & MS \\
\hline 12 & 17.5 & MR & 46 & 37.5 & $\mathbf{S}$ & 80 & 92.5 & HS \\
\hline 13 & 5.0 & HR & 47 & 30.0 & MS & 81 & 27.5 & MS \\
\hline 14 & 25.0 & MS & 48 & 42.5 & $\mathbf{S}$ & 82 & 25.0 & MS \\
\hline 15 & 15.0 & MR & 49 & 45.0 & $\mathbf{S}$ & 83 & 52.5 & HS \\
\hline 16 & 5.0 & HR & 50 & 7.5 & $\mathbf{R}$ & 84 & 95.0 & HS \\
\hline 17 & 12.5 & MR & 51 & 75.0 & HS & 85 & 57.5 & HS \\
\hline 18 & 30.0 & MS & 52 & 37.5 & $\mathbf{S}$ & 86 & 25.0 & MS \\
\hline 19 & 27.5 & MS & 53 & 30.0 & MS & 87 & 15.0 & MR \\
\hline 20 & 32.5 & $\mathbf{S}$ & 54 & 27.5 & MS & 88 & 50.0 & $\mathbf{S}$ \\
\hline 21 & 85.0 & HS & 55 & 95.0 & HS & 89 & 32.5 & $\mathbf{S}$ \\
\hline 22 & 85.0 & HS & 56 & 35.0 & $\mathbf{S}$ & 90 & 17.5 & MR \\
\hline 23 & 92.5 & HS & 57 & 25.0 & MS & 91 & 15.0 & MR \\
\hline 24 & 35.0 & $\mathbf{S}$ & 58 & 60.0 & HS & 92 & 92.5 & HS \\
\hline 25 & 32.5 & $\mathbf{S}$ & 59 & 32.5 & $\mathbf{S}$ & 93 & 97.5 & HS \\
\hline 26 & 40.0 & $\mathbf{S}$ & 60 & 47.5 & $\mathbf{S}$ & 94 & 65.0 & HS \\
\hline 27 & 2.5 & HR & 61 & 37.5 & $\mathbf{S}$ & 95 & 70.0 & HS \\
\hline 28 & 67.5 & HS & 62 & 37.5 & $\mathbf{S}$ & 96 & 10.0 & $\mathbf{R}$ \\
\hline 29 & 32.5 & $\mathbf{S}$ & 63 & 32.5 & $\mathbf{S}$ & 97 & 80.0 & HS \\
\hline 30 & 37.5 & $\mathbf{S}$ & 64 & 0.0 & I & 98 & 40.0 & $\mathbf{S}$ \\
\hline 31 & 87.5 & HS & 65 & 67.5 & HS & 99 & 40.0 & $\mathbf{S}$ \\
\hline 32 & 47.5 & $\mathbf{S}$ & 66 & 90.0 & HS & 100 & 15.0 & MR \\
\hline 33 & 62.5 & HS & 67 & 42.5 & $\mathbf{S}$ & - & - & - \\
\hline 34 & 77.5 & HS & 68 & 42.5 & $\mathbf{S}$ & - & - & - \\
\hline \multicolumn{9}{|c|}{ Mean LSI $=\mathbf{4 7 . 5 \%}$} \\
\hline \multicolumn{9}{|c|}{$\operatorname{LSD}_{(0.05)}=6.0$} \\
\hline Coef & tof Va & $9.0 \%$ & & & & & & \\
\hline
\end{tabular}

In conclusion, the immune, highly resistant and resistant RILs identified in the current study may possess diverse resistance genes, and thereby could be used for developing wheat varieties resistant to loose smut in breeding programs. BSA detected five SSR markers located on different wheat chromosomes that could be considered as markers associated with loose smut resistance in the tested population, suggesting that different loci could be contributed to the loose smut resistance in wheat. However, further studies are required to confirm the utility of SSRs markers identified in the study in marker-assisted selection (MAS) for loose smut resistance.

\section{REFERENCES}

Barakat MN, Al-Doss AA, Elshafei AA, Moustafa KA (2011). Identification of new microsatellite marker linked to the grain filling rate as indicator for heat tolerance genes in $\mathrm{F}_{2}$ wheat population. Aust. J. Crop Sci. 5(2): 104-110. 
(A)

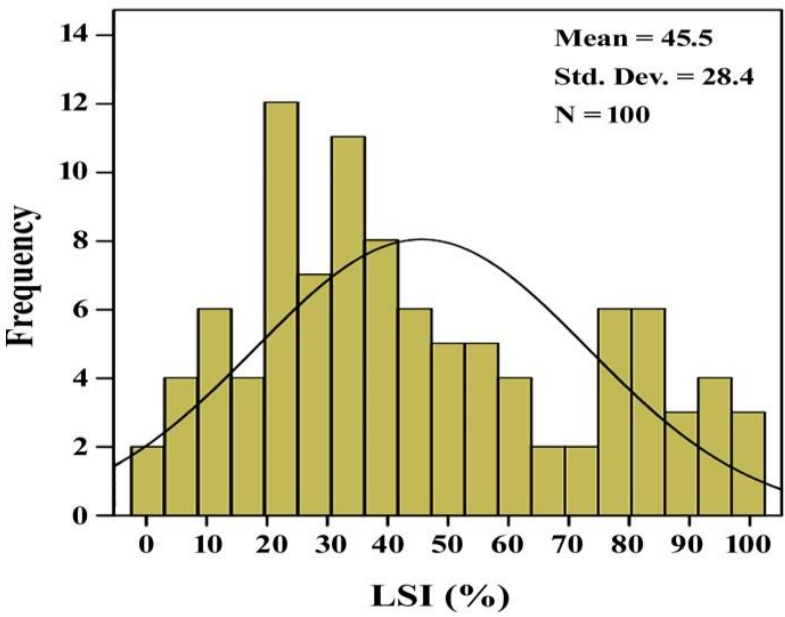

(B)

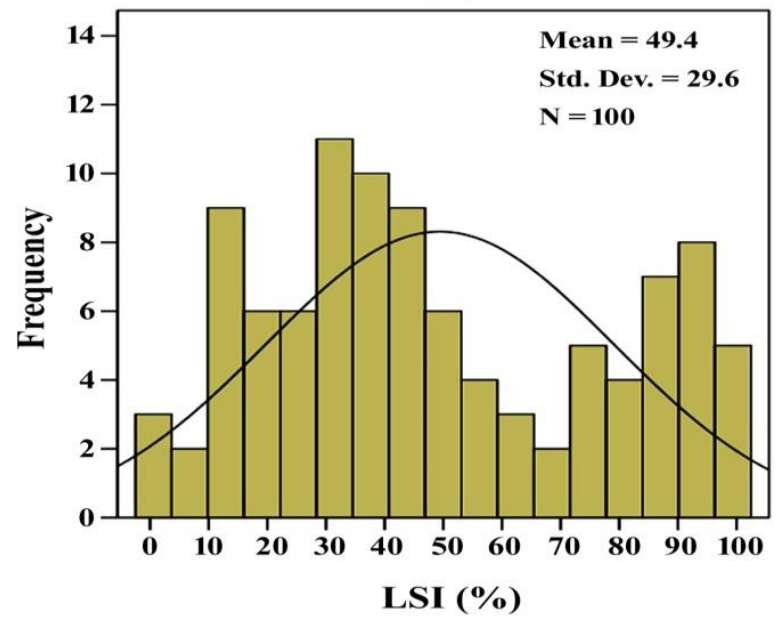

Fig.3. Frequency distribution of LSI (\%) in the RILs population in 2018/2019 (A) and 2019/2020 (B) seasons.
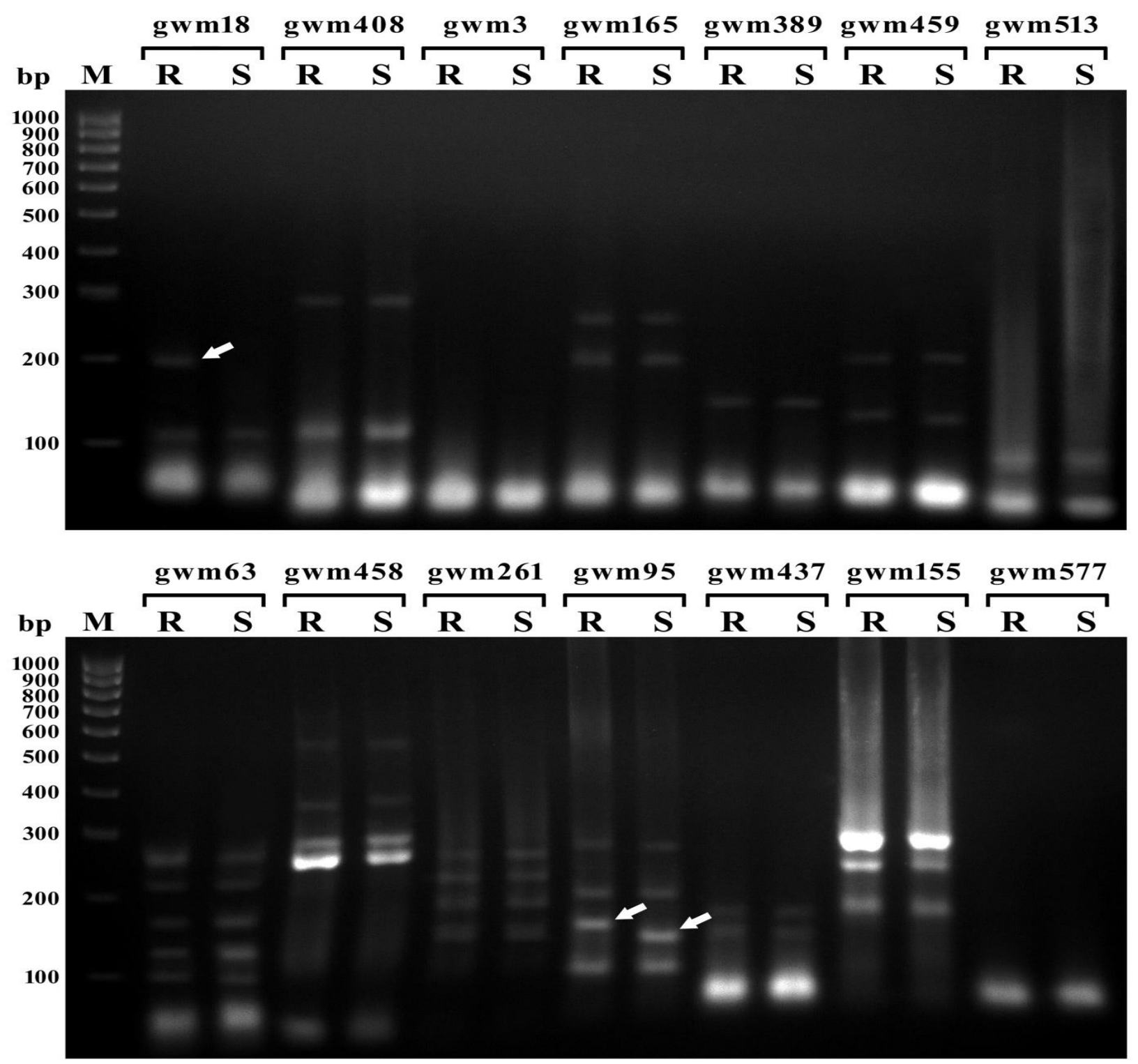

Fig.4. PCR amplifications obtained using BSA with SSR markers. M: A 100bp DNA ladder, R: Resistant bulk and S: susceptible bulk. Polymorphic bands were generated by the markers Xgwm18-1B and Xgwm952A. Arrows indicate polymorphic bands (alleles), which distinguished resistant from susceptible bulk. 

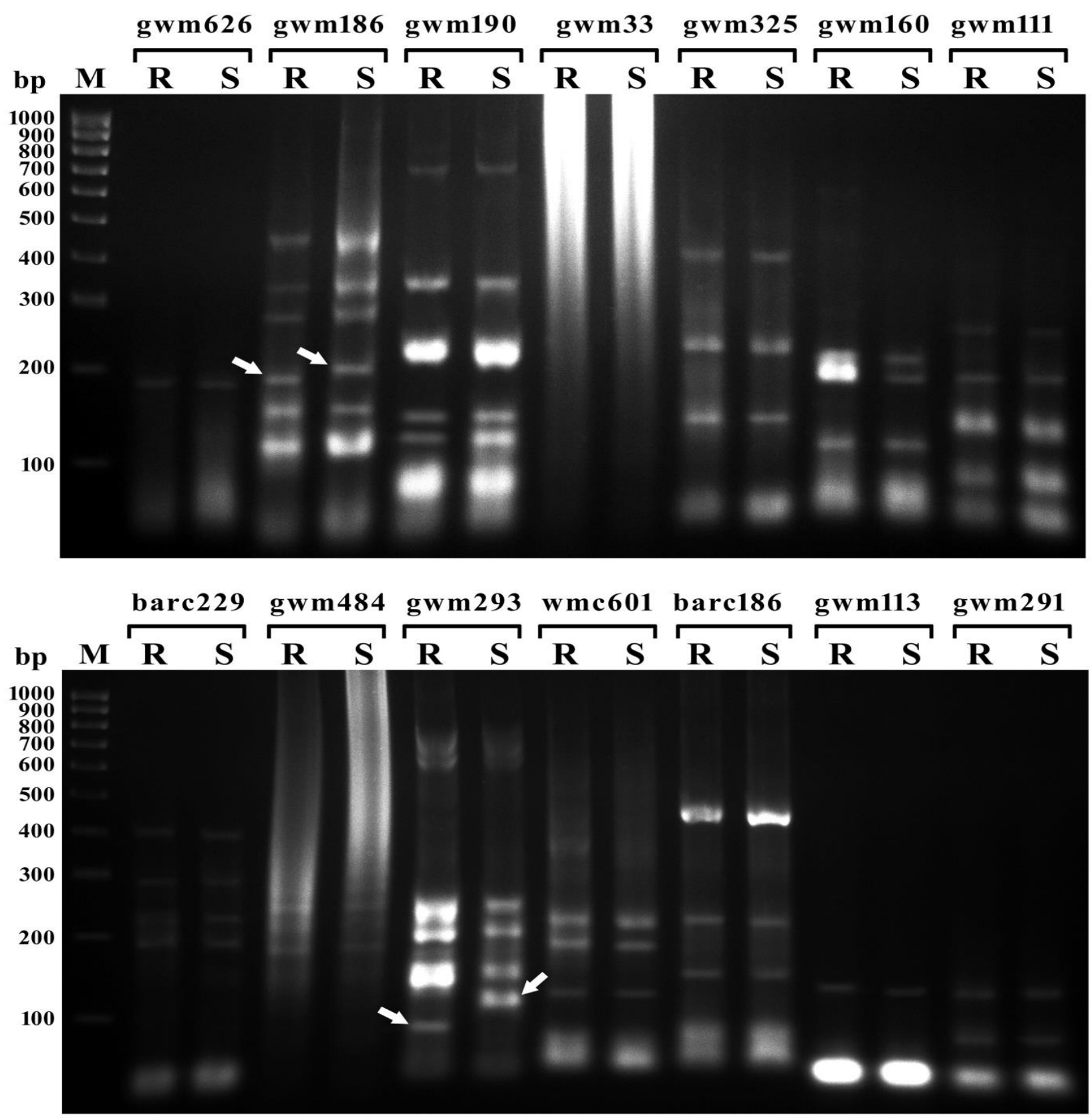

Fig.5. PCR amplifications obtained using BSA with SSR markers. M: A 100bp DNA ladder, R: Resistant bulk and S: susceptible bulk. Polymorphic bands were generated by the markers Xgwm186-5A and Xgwm2935A. Arrows indicate polymorphic bands (alleles), which distinguished resistant from susceptible bulk.

Table 4. Bands (alleles) detected for resistant and susceptible RILs using BSA.

\begin{tabular}{cccc}
\hline Marker & Chromosomal location & \multicolumn{2}{c}{ Size of positive alleles (bp) } \\
\cline { 3 - 4 } & & Resistant & Susceptible \\
\hline Xgwm18 & $\mathbf{1 B}$ & $(+) 192$ & $(+) 146$ \\
Xgwm95 & $\mathbf{2 A}$ & $(+) 160$ & $(+) 310$ \\
Xgwm294 & $\mathbf{2 A}$ & $(+) 350$ & $(+) 200$ \\
Xgwm186 & $\mathbf{5 A}$ & $(+) 188$ & $(+) 118$ \\
\hline
\end{tabular}

$(+)$ indicates a presence of a specific band (positive allele) followed by its size (bp). 

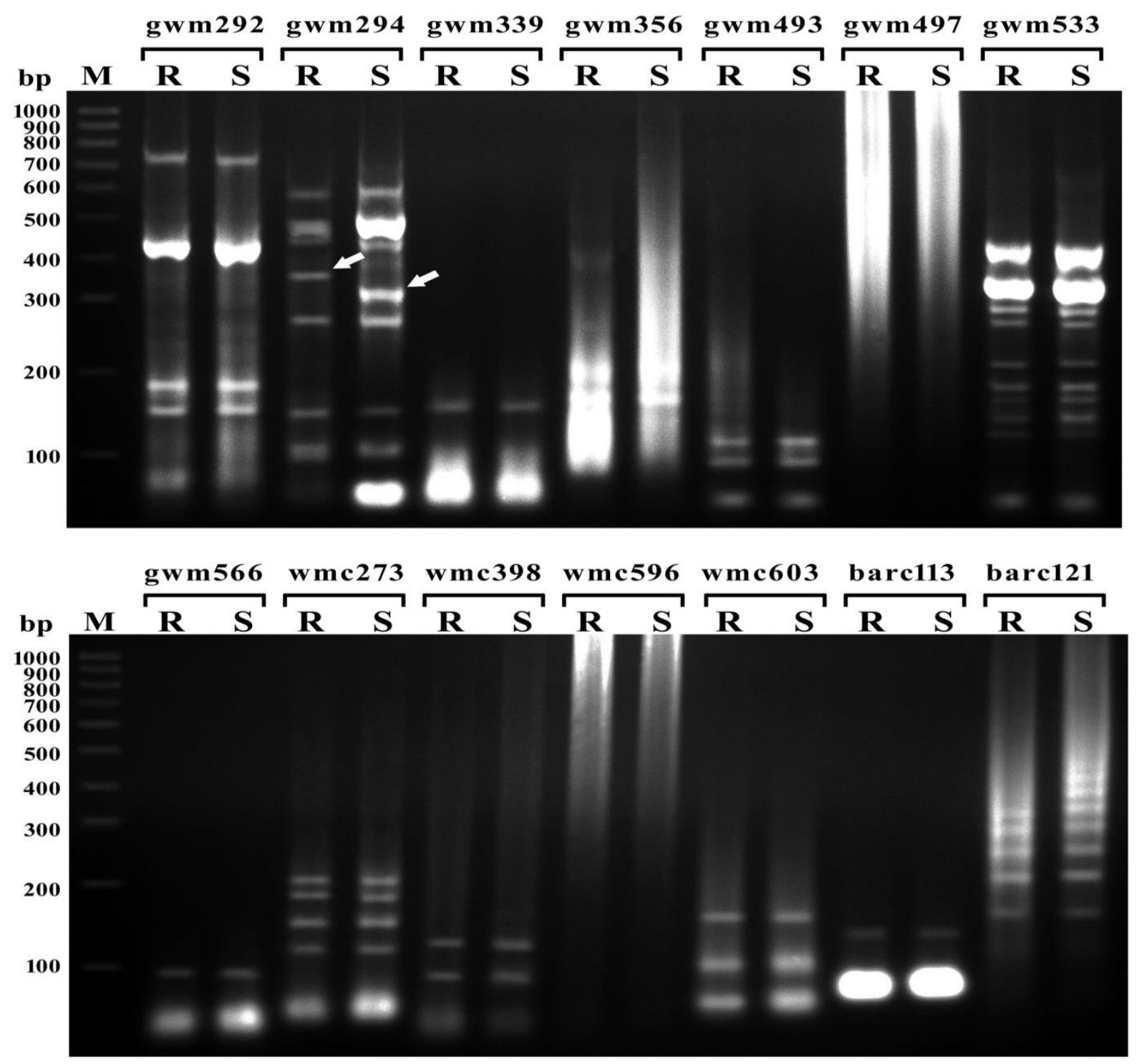

Fig.6. PCR amplifications obtained using BSA with SSR markers. M: A 100bp DNA ladder, R: Resistant bulk and S: susceptible bulk. Polymorphic bands were generated by the marker Xgwm294-2A. Arrows indicate polymorphic bands (alleles), which distinguished resistant from susceptible bulk.

Chakraborty A, Singh J, Upadhyay H (2021). Fungal diversity and ecology: major challenges for crop production in present climate scenario. In: Yadav AN (eds), Recent trends in mycological research. fungal biology. Springer, Cham.

Gad MA, El-Ghanam AA, El-Hefny DE (2019). Management of loose smut disease (Ustilago tritici) and determination of fungicides residues in wheat matrices using quechers methodology. Menoufia J. Plant Prot. 4: 107-118

Hassan MI, El-Rawy MA, Ali MA, El-Defrawy MM (2016). Phenotypic selection and bulked segregant analysis for flag leaf angle under heat stress in bread wheat (Triticum aestivum L.). Assiut J. Agric. Sci. 47 (5): 56-71.

Ilyas MB, Mirza IA, Munir AB (1990). Evaluation of inoculation methods and screening of wheat against loose smut. Pak. J. Agric. Sci. 27(3):252256.
Jaradat AA (2013). Wheat landraces: A mini review. Emir. J. Food Agric. 25 (1): 20-29.

Kassa MT, Menzies JG, McCartney CA (2014). Mapping of the loose smut resistance gene Ut6 in wheat (Triticum aestivum L.). Mol. Breeding 33: 569-576.

Kassa MT, Menzies JG, McCartney CA (2015). Mapping of a resistance gene to loose smut (Ustilago tritici) from the Canadian wheat breeding line BW278. Mol. Breeding 35: 180.

Knox R, Menzies J (2012). Resistance in wheat to loose smut. In: Sharma I. (ed.). Disease resistance in wheat. CAB International, Oxfordshire, UK.

Knox RE, Campbell HL, Clarke FR, Menzies JG, Popovic Z, Procunier JD, Clarke JM, DePauw RM, Cuthbert RD, Somers DJ (2014). Quantitative trait loci for resistance in wheat (Triticum aestivum) to Ustilago tritici. Can. J. Plant Pathol. 36:187-201. 
Knox RE, Fernandez MR, Brûleacute AL, De Pauw RM (1999). Inheritance of loose smut (Ustilago tritici) resistance in two hexaploid wheat (Triticum aestivum) lines, Can. J. Plant Pathol. 21: 174-180.

Knox RE, Menzies JG, Howes NK, Clarke JM, Aung T, Penner GA (2002). Genetic analysis of resistance to loose smut and an associated DNA marker in durum wheat doubled haploids. Can. J. Plant Pathol. 24: 316-322.

Kumar S, Knox RE, Singh AK, DePauw RM, Campbell HL, Isidro-Sanchez J, et al. (2018). High-density genetic mapping of a major QTL for resistance to multiple races of loose smut in a tetraploid wheat cross. PLoS ONE 13(2): e0192261. https://doi.org/10.1371/journal.pone.0192261.

Kumar S, Kumar M, Mir RR, Kumar R, Kumar $\mathbf{S}$ (2021). Advances in molecular markers andt use in genetic improvement of wheat. In: Wani SH, Mohan A, Singh GP (eds), Physiological, molecular, and genetic perspectives of wheat improvement. Springer, Cham.

Mahmoud AF, Hassan MI (2020). Identification of SSR markers for Fusarium head blight resistance in durum and bread wheat. Archives of Phytopathology and Plant Protection, https://doi.org 10.1080/03235408.2020.1807188.

Mahmoud AF, Hassan MI, Amein KA (2015). Resistance potential of bread wheat genotypes against yellow rust disease under Egyptian climate. Plant Pathol. J. 31: 402-413.

McIntosh RA, Yamazaki Y, Dubcovsky J, Rogers W, Morris C, Appels R, Xia XC (2013). Catalogue of gene symbols for wheat. In: Proceedings of the $12^{\text {th }}$ International wheat genetics symposium, Yokohama, Japan.

Menzies JG. (2008). Carboxin tolerant strains of Ustilago nuda and Ustilago tritici in Canada. Can. J. Plant. Pathol. 30: 498-502.

Michelmore RW, Paran I, Kesseli RV (1991). Identification of markers linked to disease-resistance genes by bulked segregant analysis: a rapid method to detect markers in specific genomic regions by using segregating populations. Proc. Natl. Acad. Sci. USA, 88: 9828-9832.

Muralidharan K, Wakeland EK (1993.) Concentration of primer and template qualitatively affects products in random-amplified polymorphic DNA PCR. Biotechniques 14(3): 362-364.

Murray MG, Thompson WF (1980). Rapid isolation of high molecular weight plant DNA. Nucleic Acids Res. 8: 4321-4325.

Nielsen J (1983). Spring wheats immune or highly resistant to Ustilago tritici. Plant Disease 67: 860863.
Nielsen J, Thomas P (1996). Loose smut. In: Wilcoxson, RD and Saari, EE (eds.), Bunt and smut diseases of wheat: concepts and methods of disease management. Mexico, D.F.: CIMMYT.

Pietrusińska A, Żurek M, Piechota U, Słowacki P, Smolińska K (2018). Searching for diseases resistance sources in old cultivars, landraces and wild relatives of cereals. A review. Agron. Sci. 73: 45-60.

Quarrie SA, Lazic-Jancic V, Kovacevic D, Steed A, Pekic S (1999). Bulk segregant analysis with molecular markers and its use for improving drought resistance in maize. J. Exp. Bot. 50: 1299-1306.

Ram SG, Thiruvengadam V, Vinod KK (2007). Genetic diversity among cultivars, landraces and 42 wild relatives of rice as revealed by microsatellite markers. J. Appl. Genet. 48: 337-345.

Randhawa HS, Popovic Z, Menzies J, Knox R, Fox $S$ (2009). Genetics and identification of molecular markers linked to resistance to loose smut (Ustilago tritici) race $\mathrm{T} 33$ in durum wheat. Euphytica 169: 151-157.

Ravi M, Geethanjali S, Sameeyafarheen F, Maheswaran M (2003). Molecular marker based genetic diversity analysis in rice (Oryza sativa L.) using RAPD and SSR Markers. Euphytica 133: 243252.

Serfing A, Kopahnke D, Habekuss A, Novakazi F, Ordon F (2017). Wheat diseases: an overview. In: Langridge $\mathrm{P}$ (ed.) Achieving sustainable cultivation of wheat-vol 1: breeding, quality traits, pests and diseases. Burleigh Dodds Sci Publ, Cambridge.

Sthapit J, Newcomb M, Bonman JM, Chen X, See DR (2014). Genetic diversity for stripe rust resistance in wheat landraces and identification of accessions with resistance to stem rust and stripe rust. Crop Sci. 54: 2131-2139.

Syukov VV, Porotkin SE (2015). Genetics of common wheat's (Triticum aestivum L.) resistance to loose smut (Ustilago tritici (Pers.) Jens.) review. Russ. J. Genet. Appl. Res. 5: 55-59.

Thambugala D, Menzies JG, Knox RE, Campbell HL, McCartney CA (2020). Genetic analysis of loose smut (Ustilago tritici) resistance in Sonop spring wheat. BMC Plant Biol. 20, 314.

Toor A, Bansal U, Bariana H (2013). Mapping of flag smut resistance in common wheat. Mol. Breeding 32: 699-707.

Torres AM, Avila CM, Gutierrez N, Palomino C, Moreno MT, Cubero J (2010). Marker-assisted selection in faba bean (Vicia faba L.). Field Crops Res. 115: 243-252.

Yadav R, Anupriya, Shekhawat PS (2020). Loose smut of wheat caused by Ustilago tritici and its management. Biotica Res. Today 2(12): 1311-1313. 
الملخص العربي

\title{
تحليل ضم الإنعزالات المتفارقة لتحديد واسمات جزيئية SSR لمقاومة التفحم السائب في قمح الخبز
}

\author{
محمد إبراهيم محمد حسن' و عامر فايز أحمد محمود' و كرم عبد النعيم أمين' \\ ' قسم الوراثة - كلية الزراعة - جامعة أسيوط - جمهورية مصر العربية

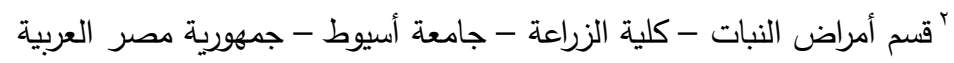

أجريت الدراسة الحالية بهدف تقييم مائة سلالة مرباة داخلياً ذات اتحادات وراثية جديدة في الجيل الثامن ناتجة من التهجين بين سلالتين

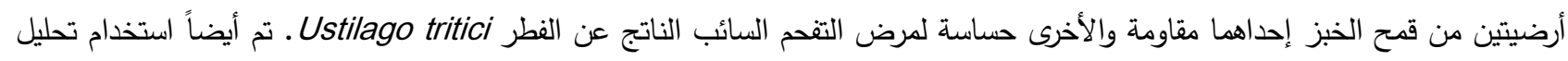

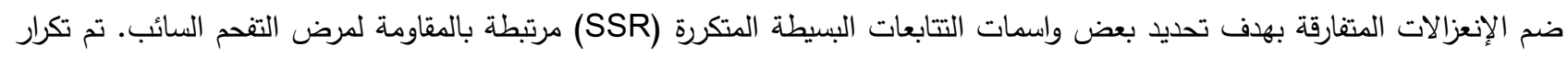

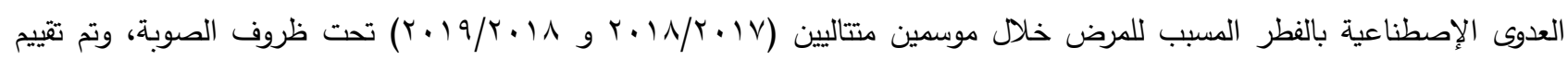

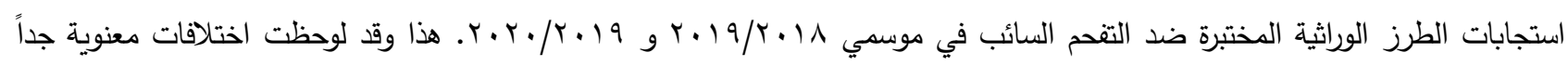

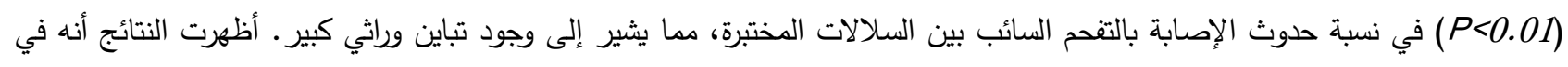

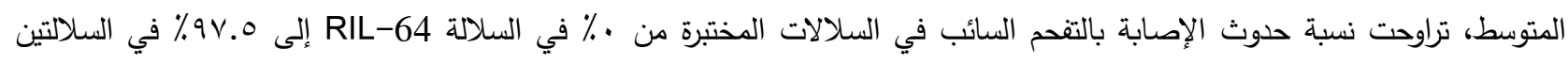

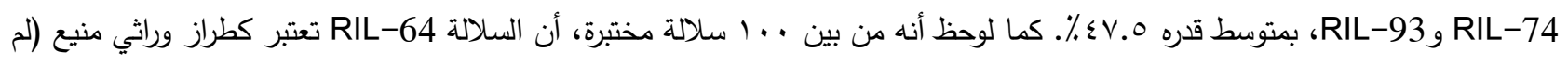

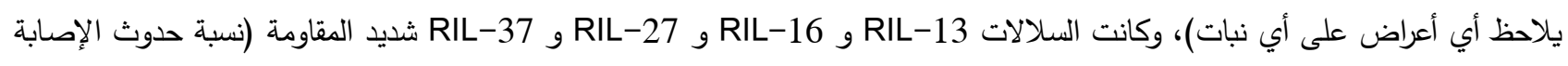

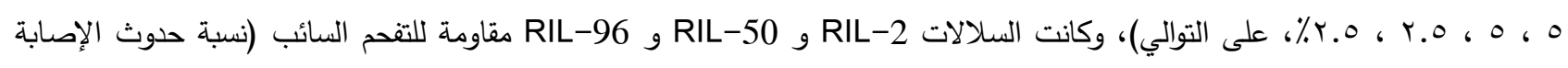

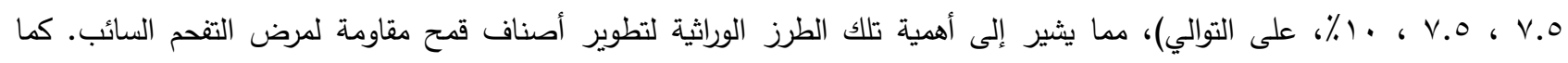

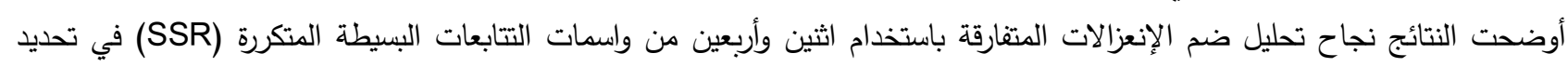
خمس أليلات نتجت بواسطة الواسمات Xgwm18-1B و Xgwm294-2A و Xgwm95-2A و و

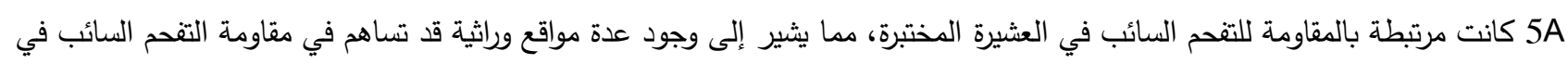

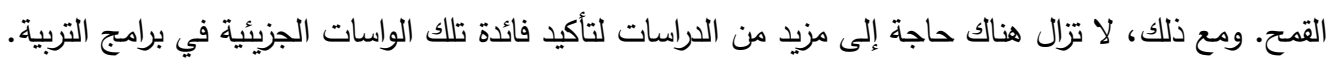

